\title{
Models for predicting frictional properties of rapeseed $* *$
}

\author{
Qian Xu ${ }^{1,2}$, Xuduo Cheng ${ }^{1,2}$, Xue Chen ${ }^{1,2}$ \\ ${ }^{1}$ Department of Food Science and Engineering, Nanjing University of Finance and Economics, Nanjing, China \\ ${ }^{2}$ Collaborative Innovation Centre for Modern Grain Circulation and Safety, Nanjing, China
}

Received, December 24, 2017; accepted June 12, 2018

\begin{abstract}
A bstract: By using rapeseed as a model material, we determined the internal friction angle and the friction coefficient against different surface types, by means of direct shear apparatus. We also established predictive models by fitting the experimental data. The internal friction angle of rapeseed ranged from $23.91 \pm 0.28$ to $34.99 \pm 1.08^{\circ}$. It decreased with normal stress ( 25 to $100 \mathrm{kPa}$ ), and increased with the moisture content $(6.58$ to $11.16 \%$ wet basis). The friction coefficient against a surface of stainless steel, wood and concrete ranged from $0.25 \pm 0.01$ to $0.50 \pm 0.03$, $0.34 \pm 0.00$ to $0.56 \pm 0.00$, and $0.40 \pm 0.00$ to $0.56 \pm 0.06$, respectively. A decrease in the friction coefficient was observed with increased normal stress (25 to $100 \mathrm{kPa}$ ). The friction coefficient tended to increase when the moisture content grew from 6.58 to $11.16 \%$ (a wet basis). When it comes to comparing the values of the friction coefficients of different friction materials, stainless steel had the lowest friction, followed by wood and concrete. Models were developed based on the obtained data, and the simulated values agreed well with the experimental data. These models can quickly predict the internal friction angle and friction coefficient values.

Keywords: internal friction angle, friction coefficient, normal stress, moisture content, predictive models
\end{abstract}

\section{INTRODUCTION}

Seeds are often subject to pressure and friction in the harvest, handling, storage and transportation processes. For example, in silos pressures tend to increase with the growing grain depth. If both pressure and friction are high enough, the stored grains or legumes can be damaged or become more susceptible to microbial or pest attacks (Bagheri and Dehpour, 2011). In addition, lateral pressures occur on silo walls due to the stacking of grains or legumes. The magnitude of these lateral pressures has a direct bearing on the safety, reliability, economy and rationality of the

\footnotetext{
*Corresponding author e-mail: chengxuduo@hotmail.com

**This work was supported by the National Natural Science Foundation of China, grant number 31371865 (2014 to 2017), funded by the Priority Academic Program Development of Jiangsu Higher Education Institutions (PAPD) (2015 to 2020).
}

silo structure. In many countries, accidents have occurred, such as cracks or collapse of the silo bodies, due to the insufficient consideration of load in the design process (Kieselbach, 1997; Mavrot et al., 2003). In global terms, 13 million tonnes of grain are lost annually due to insect damage, while 100 million $t$ are lost due to the improper grain storage (Shankar and Abrol, 2012). Therefore, a reduction of the grain/legume loss caused by improper storage could contribute to saving food that proves necessary for feeding the ever-growing human population.

In order to predict the distribution of stress in a silo, the internal friction angle and the friction coefficient are required. The accurate determination of internal friction angles and friction coefficients is essential to calculate the lateral pressure on silo walls. According to Rankine (1856), the ratio of the lateral pressure to the vertical pressure is related to the internal friction angle. Stable slopes and hang-ups in silos strongly depend on both the internal friction angle and the friction coefficient (Johanson, 1972). The liquidity level of grains is determined on the basis of the friction coefficient. If we know the frictional properties related to interactions between grains/legumes and the storage structure, we can optimize the silo design and equipment construction.

Friction is a complex phenomenon influenced by many factors. Most studies focus on the moisture-dependent frictional properties. We chose three parameters: moisture content, normal stress and frictional materials to study frictional properties, with rapeseed as a model material. Rapeseed was selected because it is an edible vegetable oil with an annual production of 72.5 million $t$.

(C) 2019 Institute of Agrophysics, Polish Academy of Sciences 
In this experiment, the internal friction angle and the friction coefficient were measured against stainless steel, wood and concrete surfaces, using direct shear apparatus. Models to predict the internal friction angle and the friction coefficient were developed using the experimental data.

\section{MATERIALS AND METHODS}

Rapeseed was purchased from a local market (Nanjing, China) and manually cleaned to remove any impurities. The mean diameter of the rapeseed kernels was $2.01 \mathrm{~mm}$ $(\mathrm{n}=100 \pm 0.09 \mathrm{~mm})$.

The moisture content was determined using the standard oven method (ASAE, 2001). In brief, $10 \mathrm{~g}$ of a pre-weighed sample was dried in an oven at $130^{\circ} \mathrm{C}$ for $0.7 \mathrm{~h}$. The moisture content was then calculated, based on the change in the mass before and after drying. The initial moisture content of rapeseed was $8.15 \%$ (a wet basis). The samples were adjusted to the desired moisture contents of 9.68 and $11.16 \%$ (a wet basis) by adding distilled water, as described by Balasubramanian (2001), or by drying (if the desired moisture was lower than the original):

$$
Q=\frac{M_{i}\left(W_{f}-W_{i}\right)}{\left(100-W_{f}\right)},
$$

where: $Q$ is the mass of distilled water required $(\mathrm{kg}), M_{i}$ is the mass of rapeseed $(\mathrm{kg}), W_{i}$ is the initial moisture content of rapeseed (\% wet basis), and $W_{f}$ is the desired moisture content of rapeseed ( $\%$ wet basis). The frictional properties were determined at the moisture content of $6.58,8.15$, 9.68 and $11.16 \%$ (a wet basis). After adjustment, the samples were placed in sealed bags and kept in an artificial air box at $5^{\circ} \mathrm{C}$ for a week. Then, the samples were equilibrated at room temperature for $2 \mathrm{~h}$ before each experiment (Deshpande et al., 1993).

The internal friction angles of rapeseed were measured using direct shear apparatus (Nanjing Soil Instruments Co., Ltd., Nanjing, China) (with automatic data collection) (Fig. 1).

The apparatus has shear boxes, each consisting of an upper and lower cell. Two types of shear boxes, i.e. a square shear box and a circular shear box, can be used in direct shear testing. According to Moya et al. (2013), no significant differences were observed between these two types of shear boxes. Therefore, the square shear box with a side length of $100 \mathrm{~mm}$ was selected for our study.

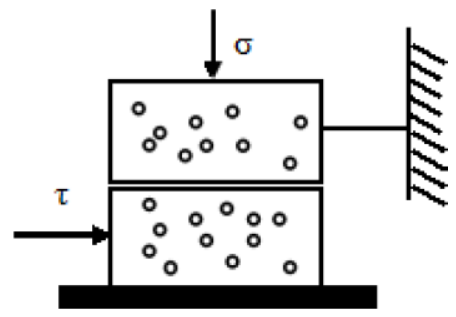

Fig. 1. Direct shear apparatus.
In the direct shear experiment, seeds were easily constrained by the box wall, which was likely to affect the experimental results. Therefore, it proved necessary to set a certain gap between the upper and lower boxes before the shear could begin. Based on the rapeseed size, a gap dimension of $2 \mathrm{~mm}$ was determined.

To begin this test, the sample was poured into the test box, and normal stress parameters of 25, 50, 75 and $100 \mathrm{kPa}$ were applied, corresponding to the actual conditions found in silos.

Rapeseed belongs to a category of non-cohesive solids. So, the fast shear experimental speeds of non-cohesive soils could be used as the reference shear speed in this paper. In order to simulate the actual conditions of rapeseed in silos, the selected shear speed should be as low as possible, so the shear speed of $1.33 \mathrm{~mm} \mathrm{~min}^{-1} \mathrm{~s}$ was selected.

1. Four coins were placed in the corners of the lower shear box to meet the requirement of a $2 \mathrm{~mm}$ gap. Two screws were then inserted into the holes of the shear boxes to fix them.

2. The sample was poured into the test box and we made sure the surface was even. Cover plates and pressure caps were placed over the sample as additional measures to induce the adequate stress. On this basis, the normal stress was applied through the air compressor.

3. The shear speed was adjusted by the hand-wheel of the direct shear apparatus. After pulling out the locating screws, the experiment could begin. Three replications were performed for each sliding surface, moisture content and normal stress.

According to Mohr-Coulomb's theory, the internal friction angle is defined as:

$$
\varphi=\arctan \left(\frac{\tau-c}{\sigma}\right),
$$

where: $\varphi$ is the angle of internal friction $\left(^{\circ}\right), \tau$ is the shear stress $(\mathrm{kPa}) ; c$ is the cohesion of the bulk solids $(\mathrm{kPa})$ and $\sigma$ is the normal stress $(\mathrm{kPa})$. The cohesion of rapeseed was found to increase with the moisture content. However, the experimental moisture content was relatively low, and the cohesion was relatively small. Assuming that rapeseed displayed no cohesion, we used the maximum shear force to determine the internal friction of the bulk solids. It means $c=0$. Then, Suthar and Das (1996):

$$
\varphi=\arctan (\tau / \sigma) .
$$

The method employed in determining the friction coefficient was similar to that used for the internal friction angle. The difference was that the shear force between the grain and different frictional materials was measured. The friction coefficient is calculated as:

$$
\mu=\tau / \sigma .
$$




\section{RESULTS AND DISCUSSION}

Table 1 provides the mean values of internal friction angles and standard deviations.

According to the data in the Table 1, the internal friction angles ranged from $23.91 \pm 0.28$ to $34.99 \pm 1.08^{\circ}$. When the normal stress increased, the internal friction angle tended to decrease. With a fixed normal stress, the internal friction angles of rapeseed increased with the moisture content.

The published data support the relationship between the moisture content and the internal friction angle. Horabik and Molenda (2002) reported that the internal friction angles of lentils increased 1.4 times when moisture content rose from 10 to $20 \%$. With such moisture contents, the internal friction angles of wheat also increased from 26 to $35^{\circ}$ (Molenda et al., 2006).

A model was developed to fit the internal friction angle, moisture content and normal stress parameters.

The relationship between the internal friction angle and the moisture content is linear and can be expressed as Eq. (5) when normal stress is lower than $25 \mathrm{kPa}$ (Fig. 2):

$$
\varphi_{0}=1.64 M C+16.67 \mathrm{R}^{2}=0.99,
$$

with normal stress of $100 \mathrm{kPa}$, internal friction angles can be calculated by a linear Eq. (6) (Fig. 2):

$$
\varphi_{\min }=0.57 M C+20.33 \quad \mathrm{R}^{2}=0.98
$$

Based on the above, the following model was proposed to simulate the relationship of the internal friction angle with both the moisture content and normal stress:

$$
\varphi=\varphi_{0}+\left(\varphi_{\min }-\varphi_{0}\right)\left(1-e^{-\lambda(\sigma-25)}\right),
$$

where $\lambda$ is the model constant. Eq. (7) can be rewritten as Eq. (8) to evaluate the model constant value $\lambda$ :

$$
\ln \left(1-\frac{\varphi-\varphi_{0}}{\varphi_{\min }-\varphi_{0}}\right)=-\lambda(\sigma-25)
$$

According to Eq. (8), $\ln \left(1-\frac{\varphi-\varphi_{0}}{\varphi_{\min }-\varphi_{0}}\right)$ was taken as the ordinate, $(\sigma-25)$ as the abscissas, and the negative value of linear regression linear slope is the model constant $\lambda$. The result shows that the value of $\lambda$ is 0.0349 . The model of the internal friction angle with both the moisture content and normal stress can be obtained by combining Eq. (5) with Eq. (7). The experimental values and the simulated values were both plotted in Fig. 3 to analyse the differences between them:

\begin{tabular}{|c|c|c|c|c|c|c|c|c|}
\hline \multirow{4}{*}{$\begin{array}{l}\text { Moisture content } \\
\text { (\% wet basis) }\end{array}$} & \multicolumn{8}{|c|}{ Internal friction angles $\left(^{\circ}\right)$} \\
\hline & \multicolumn{8}{|c|}{ Normal stresses $(\mathrm{kPa})$} \\
\hline & \multicolumn{2}{|c|}{25} & \multicolumn{2}{|c|}{50} & \multicolumn{2}{|c|}{75} & \multicolumn{2}{|c|}{100} \\
\hline & Mean & $\mathrm{SD}$ & Mean & $\mathrm{SD}$ & Mean & $\mathrm{SD}$ & Mean & SD \\
\hline 6.58 & 27.45 & 1.81 & 25.221 & 0.71 & 24.39 & 0.00 & 23.91 & 0.28 \\
\hline 8.15 & 30.11 & 1.21 & 27.47 & 0.90 & 26.26 & 1.06 & 25.17 & 0.00 \\
\hline 9.68 & 32.60 & 1.63 & 28.81 & 0.62 & 27.27 & 0.35 & 25.87 & 0.33 \\
\hline 11.16 & 34.99 & 1.08 & 29.68 & 0.61 & 27.87 & 0.35 & 26.56 & 0.79 \\
\hline
\end{tabular}

$$
\varphi=(0.57 M C+20.33)+(1.08 M C-3.66) e^{-0.0349(\sigma-25)} .
$$

Table 1. Internal friction angle of rapeseeds
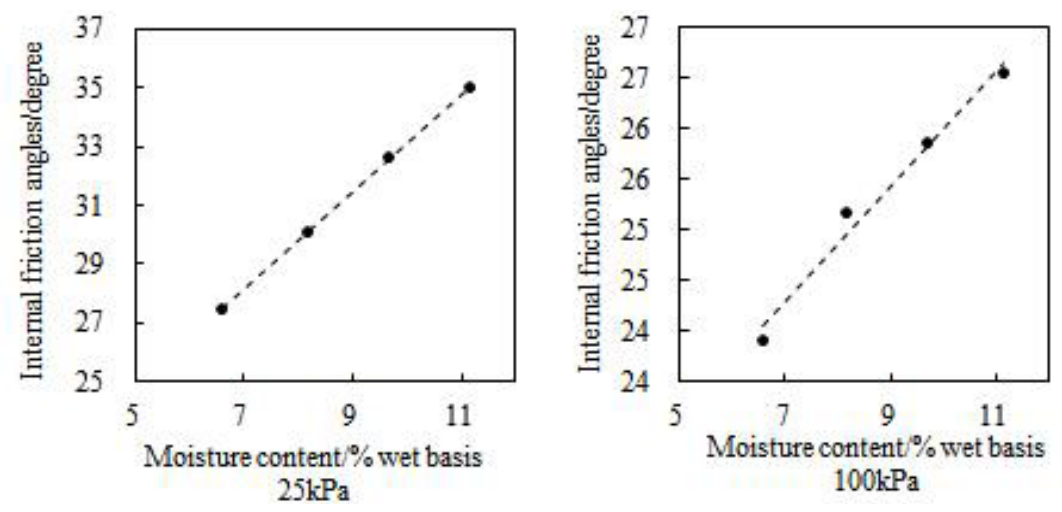

Fig. 2. Internal friction angle (normal stress of 25 and $100 \mathrm{kPa}$ ). 


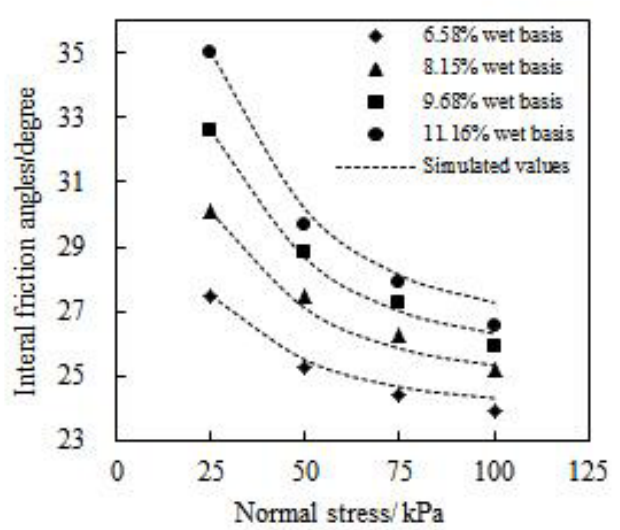

Fig. 3. Variation of the internal friction angle with both the moisture content and normal stress.

Based on Fig. 3, a relatively high consistency was obtained between the experimental and simulated data for the internal friction angle. The errors in different moisture content values $(6.58,8.15,9.68$ and $11.16 \%$ wet basis) were $0.99,0.94,0.83$ and $1.29 \%$.

Table 2 provides the friction coefficients of rapeseed against different frictional materials.

The friction coefficient against stainless steel, wood and concrete materials ranged from $0.25 \pm 0.01$ to $0.50 \pm 0.03$, $0.34 \pm 0.00$ to $0.56 \pm 0.00,0.40 \pm 0.00$ to $0.56 \pm 0.06$, respectively. Stainless steel had the lowest friction, followed by wood and concrete. These results are due to the roughness of the frictional materials. Stainless steel has a very smooth surface while wood and concrete are comparatively rough- er. Stainless steel also offered the lowest friction coefficient for other varieties of rapeseed (Izliet al., 2009; Unal et al., 2009).

For each material, the friction coefficient increased with a rise in the moisture content and decreased with a rise in normal stress. The reason for the increased friction coefficient at higher moisture contents may be caused by the moisture offering a cohesive force on the contact surface. Cohesion generally increases with moisture (Fitzpatrick et al., 2004). In addition, the higher normal stress makes the friction contact surface much smoother, thus decreasing the friction coefficient of grains.

Based on the above observations, the following method was proposed for predicting friction coefficient by fitting the experimental data.

The values of the friction coefficient against a surface of stainless steel, wood and concrete can be calculated by linear equations under normal stress of $25 \mathrm{kPa}$ (Fig. 4).

$$
\begin{aligned}
& \mu_{0_{1}}=0.026 M C+0.198 \mathrm{R}^{2}=0.98, \\
& \mu_{0_{2}}=0.035 M C+0.170 \mathrm{R}^{2}=0.99, \\
& \mu_{0_{3}}=0.009 M C+0.464 \mathrm{R}^{2}=0.96,
\end{aligned}
$$

with normal stress of $100 \mathrm{kPa}$, the relationship between the friction coefficient and the moisture content can be approximately fitted as: (Fig. 5)

$$
\begin{aligned}
& \mu_{\text {min }_{1}}=0.008 M C+0.197 \mathrm{R}^{2}=0.99, \\
& \mu_{\text {min }_{2}}=0.008 M C+0.288 \mathrm{R}^{2}=0.96,
\end{aligned}
$$

\begin{tabular}{|c|c|c|c|c|c|c|c|c|c|c|c|c|}
\hline \multirow{3}{*}{$\begin{array}{l}\text { Moisture } \\
\text { content } \\
\text { (\% wet basis) } \\
\text { (stainless steel) }\end{array}$} & \multicolumn{8}{|c|}{ Friction coefficient } & \multirow{2}{*}{\multicolumn{4}{|c|}{ Friction coefficient (concrete) }} \\
\hline & \multicolumn{4}{|c|}{ Stainless steel } & \multicolumn{4}{|c|}{ Wooden board } & & & & \\
\hline & 25 & 50 & 75 & 100 & 25 & 50 & 75 & 100 & 25 & 50 & 75 & 100 \\
\hline \multirow{2}{*}{6.58} & 0.38 & 0.29 & 0.27 & 0.25 & 0.40 & 0.36 & 0.35 & 0.34 & 0.52 & 0.44 & 0.41 & 0.40 \\
\hline & $0.03 *$ & $0.01 *$ & $0.00^{*}$ & $0.01 *$ & $0.06^{*}$ & $0.00 *$ & $0.01 *$ & $0.00^{*}$ & $0.06^{*}$ & $0.00^{*}$ & $0.01 *$ & $0.00 *$ \\
\hline \multirow{2}{*}{8.15} & 0.40 & 0.31 & 0.28 & 0.26 & 0.46 & 0.39 & 0.37 & 0.36 & 0.53 & 0.46 & 0.43 & 0.41 \\
\hline & $0.00^{*}$ & $0.01 *$ & $0.01 *$ & $0.01 *$ & $0.03 *$ & $0.01 *$ & $0.01 *$ & $0.01 *$ & $0.02 *$ & $0.00 *$ & $0.01 *$ & $0.01 *$ \\
\hline \multirow{2}{*}{9.68} & 0.44 & 0.34 & 0.29 & 0.27 & 0.52 & 0.41 & 0.39 & 0.37 & 0.50 & 0.47 & 0.45 & 0.43 \\
\hline & $0.06^{*}$ & $0.00 *$ & $0.00 *$ & $0.01 *$ & $0.00 *$ & $0.01^{*}$ & $0.00 *$ & $0.01^{*}$ & $0.03 *$ & $0.01 *$ & $0.01 *$ & $0.00^{*}$ \\
\hline \multirow{2}{*}{11.16} & 0.50 & 0.36 & 0.31 & 0.28 & 0.56 & 0.43 & 0.41 & 0.38 & 0.56 & 0.49 & 0.46 & 0.45 \\
\hline & $0.03^{*}$ & $0.00 *$ & $0.01 *$ & $0.00 *$ & $0.00 *$ & $0.01 *$ & $0.01 *$ & $0.00 *$ & $0.06^{*}$ & $0.01 *$ & $0.01 *$ & $0.01 *$ \\
\hline
\end{tabular}

Table 2. Friction coefficient of rapeseeds

*Figures are standard deviation. 

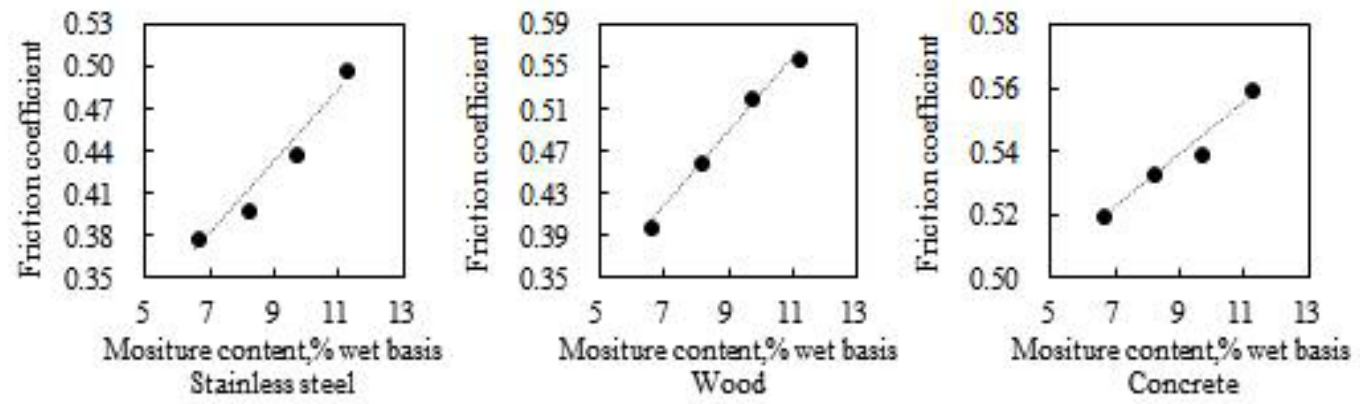

Fig. 4. Friction coefficient (normal stress of $25 \mathrm{kPa}$ ).
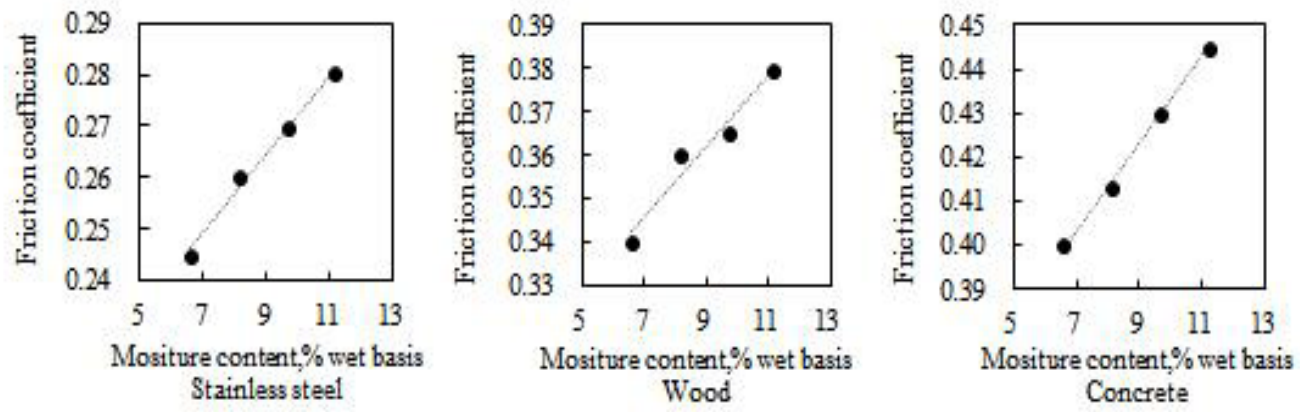

Fig. 5. Friction coefficient (normal stress of $100 \mathrm{kPa}$ ).

$$
\mu_{\text {min }_{3}}=0.010 M C+0.334 \mathrm{R}^{2}=0.99 .
$$

Eq. (16) was selected to simulate the relationship of the friction coefficient with both the moisture content and normal stress:

$$
\mu=\mu_{0}+\left(\mu_{\min }-\mu_{0}\right)\left(1-e^{\varepsilon(\sigma-25)}\right),
$$

where: $\varepsilon$ is model constant. Eq. (16) can be changed into:

$$
\ln \left(1-\frac{\mu-\mu_{0}}{\mu_{\min }-\mu_{0}}\right)=-\varepsilon(\sigma-25) \text {. }
$$

According to Eq. (17), $\ln \left(1-\frac{\mu-\mu_{0}}{\mu_{\min }-\mu_{0}}\right) \quad$ was taken as the ordinate, $(\sigma-25)$ as the abscissa, the negative value of the linear regression slope is the model constant $\varepsilon$. The results show that the values of $\varepsilon$ for stainless steel, wood and concrete are $0.0378,0.0408$ and 0.041 , respectively. The model of variation of the friction coefficient with both the moisture content and normal stress can be obtained by combining Eq. (10) with (16). The experimental values and the simulated values were both plotted in Fig. 6 to intuitionally analyse the differences between them:

$\mu_{\text {stainless steel }}=(0.008 M C+0.197)+(0.0185 M C+0.001) e^{-0.0378(\sigma-25)}$,

$\mu_{\text {wood }}=(0.008 M C+0.288)+(0.0272 M C+0.118) e^{-0.0408(\sigma-25)}$,

$\mu_{\text {concrete }}=(0.01 M C+0.334)+(0.0016 M C+0.131) e^{-0.041(\sigma-25)}$.

Based on Fig. 6, the simulated values of the models agree well with the experimental data. The maximum error between the simulated value and the experimental value for different surfaces (stainless steel, wood and concrete) was $4.40,4.42$ and $1.89 \%$, respectively.

\section{CONCLUSIONS}

1. The internal friction angle of rapeseed ranged from $23.91 \pm 0.28$ to $34.99 \pm 1.08^{\circ}$. The friction coefficient against a surface of stainless steel, wood and concrete ranged from $0.25 \pm 0.01$ to $0.50 \pm 0.03,0.34 \pm 0.00$ to $0.56 \pm 0.00,0.40 \pm 0.00$ to $0.56 \pm 0.06$, respectively.

2. The internal friction angle and the friction coefficient both decreased with normal stress, and increased with the moisture content. The lowest friction coefficient was offered by stainless steel, followed by wood and concrete.

3. The values of the internal friction angle can be obtained as: $\varphi=(0.57 M C+20.33)(1.08 M C-3.66) e^{-0.0349(\sigma-25)}$. The variation of the friction coefficient against a surface of stainless steel, concrete, and wood can be calculated by $\mu_{\text {stainless steel }}=(0.008 M C+0.197)+(0.0185 M C+0.001) e^{-0.0378(\sigma-25)}$, and $\mu_{\text {wood }}=(0.008 M C+0.288)+(0.0272 M C+0.118) e^{-0.0408(\sigma-25)}$, and $\mu_{\text {concrete }}=(0.01 M C+0.334)+(0.0016 M C+0.131) e^{-0.041(\sigma-25)}$.

4 . The simulated values of the models were in good agreement with the experimental data. The internal friction angle and friction coefficient values can be quickly predicted by using these models. 

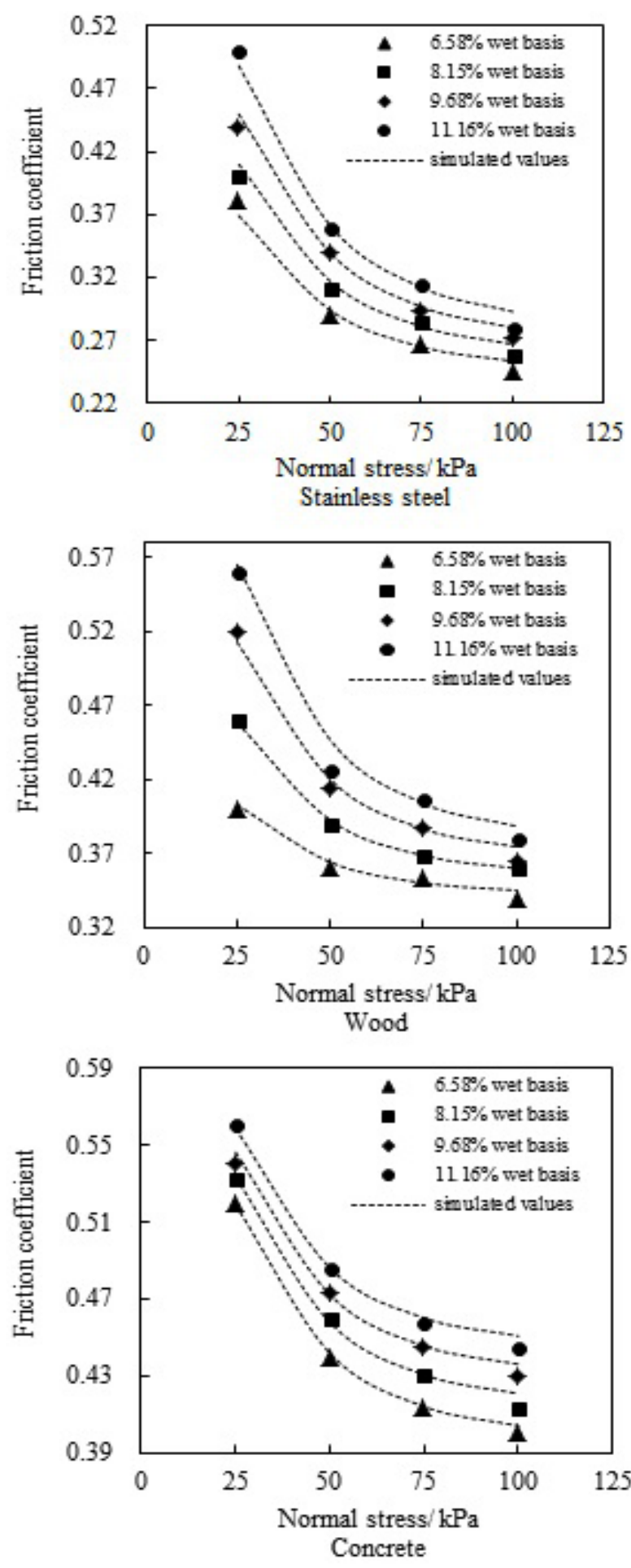

Fig. 6. Variation of the friction coefficient with both the moisture content and normal stress.

\section{ACKNOWLEDGMENT}

The authors would like to thank the National Natural Science Foundation of China for financial support, and the Nanjing University of Finance and Economics for providing the laboratory facilities for this research.

Conflict of interest: The Authors do not declare conflict of interest.

\section{REFERENCES}

ASAE, 2001. ASAE S352.2 APR1988 (R2001). Moisture measurement-unground grain and seeds. Am. Soc. Agric. Eng., 567-568.

Bagheri I. and Dehpour M.B., 2011. Effect of moisture content and loading rate on mechanical strength of brown rice varieties. World Academy of Science, Eng. Technol., 59, 1385-1391.

Balasubramanian D., 2001. PH-Postharvest technology: physical properties of raw cashew nut. J. Agric. Eng. Res., 78(3), 291-297.

Deshpande S.D., Bal S., and Ojha T.P., 1993. Physical properties of soybean. J. Agric. Eng. Res., 56(2), 89-98.

Fitzpatrick J.J., Barringer S.A., and Iqbal T., 2004. Flow property measurement of food powders and sensitivity of Jenike's hopper design methodology to the measured values. J. Food Eng., 61(3), 399-405.

Horabik J. and Molenda M., 2002. Physical properties of granular food materials. Acta Agrophysica, 74, 1-89.

Izli N., Unal H., and Sincik M., 2009. Physical and mechanical properties of rapeseed at different moisture content. Int. Agrophys., 23(2), 137-145.

Johanson J., 1972. Modeling flow of bulk solids. Powder Technology, 5, 93-99.

Kieselbach R., 1997. Bursting of a silo. Eng. Failure Analysis, 4(1), 49-55.

Mavrot G., Sochet I., Bailly P., and Moisescot M., 2003. Silo vulnerability: structural aspects. J. Loss Prevention Process Industries, 16(2), 165-172.

Molenda M., Stasiak M., Moya M., Ramirez A., Horabik J., and Ayuga F., 2006. Testing mechanical properties of food powders in two laboratories: degree of consistency of results. Int. Agrophysics, 20(1), 37-45.

Moya M., Aguado P., and Ayuga F., 2013. Mechanical properties of some granular agricultural materials used in silo design. Int. Agrophys., 27(2), 181-193.

Rankine W.J.M., 1856. On the stability of loose Earth. Philosophical Trans. Royal Society, 147(0), 9-27.

Shankar U. and Abrol D.P., 2012. Integrated Pest Management in Stored Grains. Book, Integrated Pest Management, 386-407.

Suthar S.H. and Das S., 1996. Some physical properties of karingda [Citrullus lanatus (Thumb) Mansf] seeds. J.Agric. Eng. Res., 65(1), 15-22.

Unal H., Sincik M., and Izli N., 2009. Comparison of some engineering properties of rapeseed cultivars. Industrial Crops and Products, 30(1), 131-136. 